\title{
Zoning of Unused Land of Military Facilities in Krasnodar Krai
}

\author{
Anastasia A. Melnikova ${ }^{*}$, Vladimir V. Pimenov², Kirill A. Svirezhev², \\ Denis A. Khabarov ${ }^{3}$, Irina A. Khabarova ${ }^{4}$
}

1 Department of Real Estate Economics, Faculty of Land Management, State University of Land Use Planning, 15, Kazakova str., Moscow, 105064, Russia

2 Department of Land Management, Faculty of Land Management, State University of Land Use Planning 15, Kazakova str., Moscow, 105064, Russia

3 Pedology, Ecology and Environmental Management Department, State University of Land Use Planning, 15, Kazakova str., Moscow, 105064, Russia

4 Urban Cadastre Department, State University of Land Use Planning, 15, Kazakova str., Moscow, 105064, Russia

* Corresponding author's e-mail: nastasyamelnikova@yandex.ru

\begin{abstract}
The research paper covers the features of the socio-economic and environmental diagnostics of agricultural land use. Zoning is a kind of basis for the territorial record keeping of the natural conditions and resources, quantity, quality, as well as the production capacity of lands in the system of taxonomic units. It is a natural and historical basis for the placement of agricultural production, land valuation, the development of land use patterns, land management patterns and projects, farming and agriculture systems, etc. Natural zoning reflects the need for priority land use in the interests of the economy. It has an agrobioecological basis due to the peculiarities of agricultural production, the essence of which is the utilization of the solar energy by the plant organisms necessary to maintain the ecological stability of the territory. The authors used the methods of particle-size and chemical analysis, the methods of comparing indicators for zones with various types of agriculture and soils of the military sites under the influence of the man-made factors. The main socio-economic indicators characterizing the development of land use were analyzed. The concept of state policy forms in the valuation of unused lands of Krasnodar Krai was substantiated.
\end{abstract}

Keywords: land resources, enterprises, agricultural land use, agricultural policy, natural resource potential.

\section{INTRODUCTION}

Diverse environmental studies should be concluded by a synthesis of all theoretical and practical information obtained in all blocks for the development and implementation of plans and programs for environmental management at the local, regional and global levels [Gosselin et al., 2018; Todaro et al., 2019]. The creation of the scientific foundations of environmental economics is also necessary for the formation of regional and national environmental policies [Durach and Wiengarten, 2017; Puppim de Oliveira, 2019].

The development and implementation of international programs, agreements, treaties in the field of environmental management, environmental protection and environmental education is crucial to determining the tactics and strategy of the environmentally safe development of mankind, as well as preservation of the biosphere and life on Earth [Ladyman et al., 2019; Virapongse et al., 2016].

On the basis of the need to solve the abovementioned problems, in 1990 the institute Krasnodar Zemproekt, created the scientific unit which included the Land Use Ecology Department. The Research Land Use Ecology Department (hereinafter - "the Department") had two sectors at that time. Since the creation of the Department, the research has been focused on solving the problems of ecologization of land management as a mechanism for preparing and implementing the management decisions, which is the only guarantee for 
introducing environmental ideas into the land use practices. Indeed, despite the numerous functions that are inherent in the soil, based on the increasing needs of society, it is, above all, a natural-biological formation. One of the priority tasks should be to ensure the balanced functioning of land as an ecological system in the process of its use or land use in the broad sense. Without providing the conditions for the reproduction of the properties of the soil as an ecosystem, it is unlikely that it will be able to fully serve as a means of production and recreation, living space, and the like. Scholars have determined the object and subject of the land use ecology, the objective and its main tasks.

Land use ecology is a complex scientific subject which is one of the main sections of soil science [Wallace and Jago, 2018]. The main objective of land use ecology is to ensure the sustainable production of high-quality biological products, preservation and reproduction of the natural resource base of the agricultural sector, the effective ecologization of all branches of agricultural production. On the basis, the scholars of the Department considered the surrounding nature as a foundation of life, and not as a collection of inexhaustible resources which can be used for life.

\section{MATERIALS AND METHODS}

The authors used the soil samples taken in various areas of military facilities, carried out the spectral and indicator analysis of the soil composition and accumulation of heavy metals, used the cartographic zoning methods. The dialectical method allowed considering the development of the alienation of land plots for public needs as well as for the reasons of social necessity and its connection with other legal categories.

With the help of the historical method, the authors studied the processes of land alienation for military or social needs, forms of relations of land withdrawal for public needs in different historical periods, revealed the changes in the legal regulation of land alienation for the military or social needs. The formal and logical method was used in the analysis of the provisions of civil legislation of the Russian Federation and other countries that regulate the alienation of land for public use or for social needs, the practice of their application. The method of system analysis allowed identifying the features of compensation of the value of the land and real estate objects located on it in case of alienation of land for public use or for social needs, as well as identifying the features of the land plot as an object of civil legal relations and the features of private property right to such a specific object as a land plot. The method of comparative legal analysis allowed comparing the legal regulation of the alienation of land for public use or for the reasons of social needs in Russia and foreign countries.

The research objective was to reveal the significance of the inventory in solving the environmental problems associated with the use of nonagricultural land.

\section{RESULTS AND DISCUSSION}

Rational land use, which is associated with the need to form competitive advantages, taking into account the factors that have the greatest impact on the land use efficiency, occupies a special place among the priority areas of development of the agricultural sector of Krasnodar Krai. It is necessary to reasonably determine the causes and justify the prerequisites and features of the use of the land resources that are under the administration and use of military facilities, the reformation of land relations not only from an economic, but also from an environmental point of view. The aspects of land use in the territories where military facilities are located were explored as well.

However, the authors consider it necessary to determine the features of the socio-economic and environmental assessment of the level of non-agricultural land use. The set scientific task is to justify the need for the socio-economic and environmental assessment of the level of non-agricultural land use as a prerequisite for ensuring its socioeconomic and environmental efficiency, enhancing the innovation and investment processes with the rational use of the natural resource potential. One of the main components of the methodological basis of the level of land use is the assessment of the composition and ratio of agriculturally used areas.

The most important indicator of the level of land use intensity is the proportion of land by types in the total available land. As far as the vulnerability to erosion is concerned, a small class exposed to soil erosion dominates, which indicates the dominance of the lower class in most areas. When the soil erosiveness is combined with dissected relief, this leads to a potential risk of erosion, revealing an improved situation for some 
regions due to the wide geographic expression of slopes of less than $20 \%$.

The vulnerability of soil to erosion takes into account the potential risk of erosion, precipitation intensity and the soil exposure to direct precipitation. The signs are more serious in the east, central zone and north-west with more comfortable conditions in the north, followed by the south.

The non-agricultural land is owned by nonagricultural enterprises, occupying $56.2 \%$, the land owned by citizens corresponds to $43.8 \%$. At the same time, the military enterprises do not use arable land, they are strategically important for locating bases and facilities. The management of local soil pollution in case of proven damage to the environment is aimed at reducing the harmful effects. It is implemented in several stages.

Preliminary reviews allow making a list of potentially contaminated areas and establishing the presence or absence of pollution and potential dangerous effects on the human health or the environment. The main object research is aimed at determining the degree of contamination.

The authors used the studies of the condition of soils pertaining to the object "Former military range located in Krasnodar Krai". The main objective of the research was to establish the initial level of soil pollution due to the need to comply with environmental legislation in the field of soil/land protection when planning the further use of this territory, as well as to develop a set of measures (depending on the level of pollution detected) to clean up the polluted areas and improve their ecological condition. As it is well-known, excessive concentrations of heavy metals in nature, in particular zinc, adversely affect the ecological condition of the environment, which can lead to the disruption of the physiological and biochemical processes occurring in living organisms [Ruseeva et al., 1976; Avakyan et al., 2017]. Zinc is found in air, water and soil, greatly influencing the shape and development of plants, animals and people.

The study revealed the differences in the concentrations of zinc within a small area. The results of the analysis of the water and soil samples taken in the areas of military ranges indicate an imbalance in the content of zinc ions [Bugaevsky, 2017]. This can lead to a negative change in the biochemical composition of the soil and water bodies, and the disease of the flora and fauna of these territories.

The technogenic contamination of soil with zinc in the territories of the Armavir range and the detected imbalance of its concentration outside of it prompts a thorough study on the biogeochemical situation of these areas and measures to control the movement and concentration of zinc in the watersoil-plant system in order to maintain its content at an acceptable level. Increased attention is paid to the soil contamination of shooting ranges with lead $(\mathrm{Pb})$ caused by shots and bullets due to the increased $\mathrm{Pb}$ content in these areas and the adverse health effects associated with the $\mathrm{Pb}$ exposure.

\section{PROBLEM STATEMENT}

On the basis of the research data obtained from the analysis of the water and soil samples from the areas adjacent to the military facilities of the Armavir range, this article outlines the features of zinc concentration depending on the terrain, and determines the possible directions of pollution of these areas or maintaining the zinc content at an acceptable level [Bugaevsky, 2017].

The materials of numerous publications indicate that the monitoring of zinc concentrations was carried out mainly in the areas significantly remote from the military facilities of the Armavir range [Bugaevsky, 1971; Ruseeva et al., 1976; Avakyan et al., 2017]. High levels of zinc ion concentrations were found as a result of the analysis of the water and soil samples in the territories adjacent to the military ranges.

The above issues related to the instability of zinc concentration and the implementation of measures to control the zinc content in water bodies and soils at an acceptable level. In accordance with the requirements of the Armavir Natural Environment Protection Program, the research related to the identification of the areas contaminated with heavy metals, including zinc, is carried out more intensively. Such measures are implemented in the general monitoring system and are aimed at normalizing the concentration of zinc, in particular in the water bodies and soils near the military facilities of Krasnodar Krai, and maintaining this concentration at an acceptable level [Cherednichenko, 1994].

Uncontrolled movement of zinc in the "water-soil-plant" system can lead to irreversible negative consequences. During the sampling of the water and soil from the military ranges, attention was paid to the surrounding terrain. The results showed that - depending on the topography - vegetation and distance from water bodies, the values of zinc concentration fluctuate in a considerable range. Among these military facilities, the 
Armavir military range is of the greatest interest, since the characteristics of the zinc content in the waters and soils near it substantially depend on the nature of the terrain.

It is obvious that complex compounds with organic substances of the soil formed with the participation of zinc, so they are less available for absorption in the soil with a high content of humus. The excess moisture in the soil contributes to the transition of this trace element to low oxidation levels and soluble forms. Therefore, the drainage systems that correct the water regime contribute to an increase in the content of the oxidized forms of zinc and thereby reduce its migration characteristics. The object under study is the territory of a fuel and lubricant warehouse of the former aviation base of Armavir (military range), located on the south-eastern outskirts of the city. The fuel and lubricant warehouse is located in the south-eastern part of the base, $3 \mathrm{~km}$ from the urban area.

The construction of the airfield dates back to September 1939, the remaining infrastructure of the airfield was erected in the post-war period, starting from 1946. In the post-war years, a 2,500 $\mathrm{m}$ long runway was built, and the railway supply line was connected. The total area of the military base at that time was 650.5 hectares. In addition to fighters, strategic aviation was based on the airfield. In the period from 1992 to 1994, the air base was disbanded, and by 2005 the territory of the base was transferred under the control of the Armavir City Executive Committee, and the unused lands were classified as "reserve lands" [Ruseeva et al., 1976].

The study area belongs to the southern part of Krasnodar Krai, composed mainly of moraine sandy loams and loams. The nature of the topography is gently sloping and flachwellig, the absolute heights are 170-175 m, horizontal dissection is $0.5-0.6 \mathrm{~m}$, vertical dissection $-5-10 \mathrm{~m}$. The territory under consideration is characterized by a developed hydrographic network, the source of the Urup river is in close proximity (less than $1 \mathrm{~km}$ ) from the location of the former fuel and lubricant warehouse. The groundwater table directly under the fuel and lubricant warehouse is located at depths from $1.8 \mathrm{~m}$ to $5.5 \mathrm{~m}$.

The soddy podzolic soils developing on fluvioglacial and moraine sandy loams, underlain by moraine loams, as well as the soddy podzolic soils developing on thick sands are zonal for the area under study. At the same time, the long-term anthropogenic development of the area under study has led to the formation of a reclaimed surface layer which overlaps the geological deposits of natural origin. The soil cover of the territory is homogeneous and represented by technozems the most deeply transformed soils created as a result of the removal of the upper fertile layer followed by sprinkling of the man-made soil.

The specificity of the functional purpose of the object predetermined a high risk of environmental pollution by oil products due to possible spills and leaks. The granulometric composition is primarily distinguished among the factors affecting the ability of the soil to absorb pollutants. The high content of oozy and colloidal particles (with a diameter of less than $0.001 \mathrm{~mm}$ ) and, to a lesser extent, medium and fine dust (0.01-0.001 $\mathrm{mm}$ ) is due to the significant accumulating capacity of the soil. The experimental studies show that zinc quickly accumulates in soils and water and comes out very slowly. The analysis of the soil samples taken near the military ranges, where there is no vegetation, while rainwater slightly penetrates the soil and evaporates, showed a significant content of zinc in the soil. When it is washed out and comes to the surface of the soil, it accumulates in the soil layer, especially in the upper humus horizons, and slowly disappears due to erosion, plants and leaching. The first period of the semi-destruction of elements from the soil (i.e., vanishing of half of the initial concentration) under natural conditions varies considerably. For example, for zinc - from 70 to 510 years.

Deciduous trees, grass vegetation, elements of sewer systems, and systematic watering of green plantations significantly reduce the concentration of zinc in the places of their distribution. The concentration of zinc on the shooting range, the territory of which is characterized by rugged terrain, small quantities of humus in the soil, the lack of vegetation is of particular concern. Water bodies are constantly subject to the influence of the activity of military units and form a kind of tank for the accumulation of zinc. Rainwater flowing from the range washes away the soil and brings it to the local river.

A certain part of zinc with hydrochemical flow enters the water bodies where it accumulates -settles in the bottom sediments and can become a source of secondary pollution. The heavy metal compounds spread relatively quickly in the aquatic environment. They precipitate in the form of carbonates, sulfates, being partially adsorbed. Thus, the analysis of the water and soil samples showed that the pollution of the territory 
of military facilities has a negative impact on the surrounding areas. In addition, the rugged terrain causes a certain contrast of the presence of zinc in the soil and in the aquatic environment of the territories under study (Figure 1).

The knowledge of the features of zinc distribution in the components of particular landscapes, depending on their geographical location and topography, allows taking timely and effective measures to control its concentration in the water-soil-plant system and preventing further pollution of water and soils not only of the Armavir military facility, but other similar facilities, developing and implementing the measures for their cleaning. The organization of systematic geochemical control of the surface of military facilities and adjacent territories will allow determining the dynamics of the anthropogenic impact on the soil cover and aquatic environment, the changes in the directions of migration of zinc, timely planning and implementing the measures to clean them from excessive zinc.

A well-established system of monitoring the natural and anthropogenic changes that occur in the water-soil-plant system will allow assessing the ecological condition of the environment, predicting its change and preventing the possible negative effect of zinc imbalance on humans. Studies also show that special creation of certain conditions can contribute to the stabilization and reduction of the zinc concentration in soils. The studies conducted in numerous research institutions

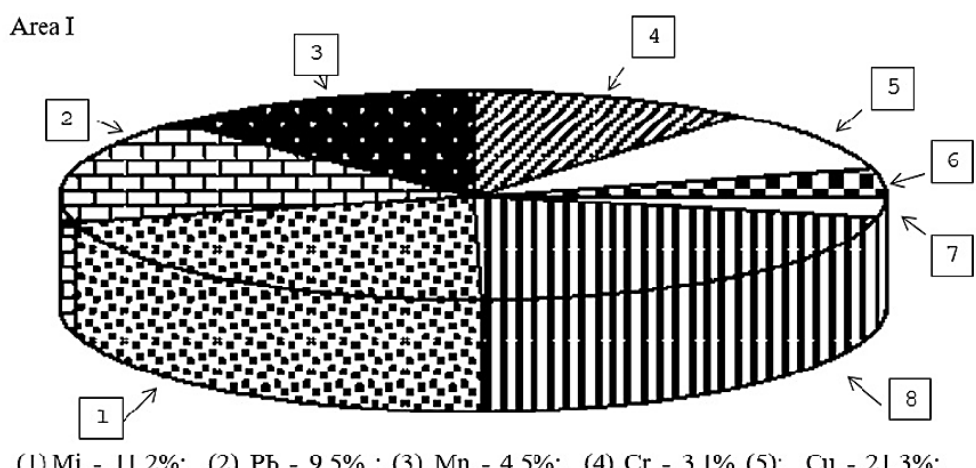

(1) $\mathrm{Mi}-11,2 \%$; (2) $\mathrm{Pb}-9,5 \%$; (3) $\mathrm{Mn}-4,5 \%$; (4) $\mathrm{Cr}-3,1 \%$ (5); $\mathrm{Cu}-21,3 \%$; (6) $\mathrm{N}-21,3 \%$; (7) $\mathrm{Cu}-16,3 \%$; (8) $\mathrm{Cn}-12,8 \%$

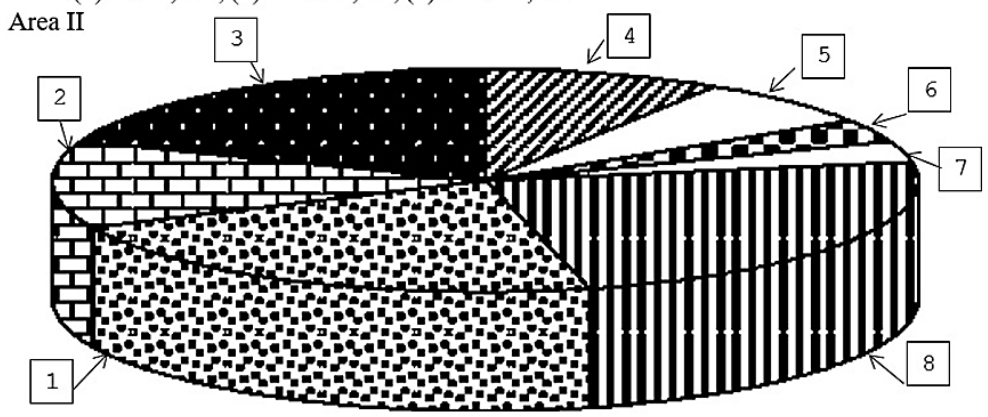

(1) $\mathrm{Mi}-8,9 \%$; (2) $\mathrm{Pb}-6,9 \%$; (3) $\mathrm{Mn}-3,3 \%$; (4) $\mathrm{Cr}-2,9 \%$ (5); $\mathrm{Cu}-24 \%$;

(6) $\mathrm{N}-21,7 \%$; (7) $\mathrm{Co}-12,7 \%$; (8) $\mathrm{Cn}-19,2 \%$

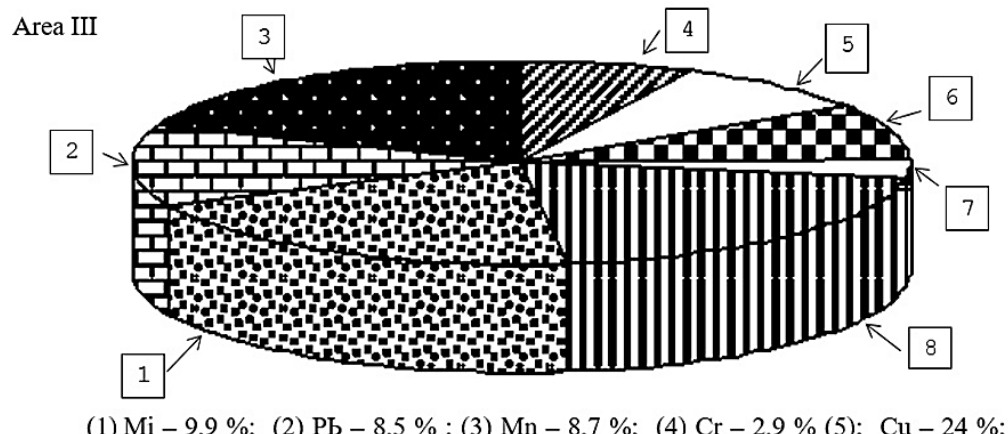

(1) $\mathrm{Mi}-9,9 \%$; (2) $\mathrm{Pb}-8,5 \%$; (3) $\mathrm{Mn}-8,7 \%$; (4) $\mathrm{Cr}-2,9 \%$ (5); $\mathrm{Cu}-24 \%$;

(6) $\mathrm{N}-21,7 \%$; (7) $\mathrm{Co}-12,7 \%$; (8) $\mathrm{Cn}-13,1 \%$

Fig. 1. Sums of coefficients of biological accumulation of metals by fractions of overground phytomass in Area I - Northern part of the city of Armavir - military range; Areas II-III - remote from the range 
have found that plants can absorb trace elements from the soil, including heavy metals, due to the active contact absorption by the roots, accumulating them in their own tissues or on the surface of leaves [Chernov, 1983; Danilov-Danilyan, 1997].

\section{CONCLUSIONS}

Experimental studies have shown that highquality cleaning of soils from heavy metals can be carried out using one- or two-year vegetation with its subsequent destruction. Depending on the composition of the soil, the nature of the root system, the intensity of the metal ions absorption by plants from the solid phase can vary hundreds and thousands of times. During the research, it was found that the content of chemical elements in plants does not depend on their concentration in the nutrient medium. This is especially true for microelements. In case of complex accumulation, a high concentration of toxic elements in sometime leads to a change in the morphology of plants, and their death.

The presented materials testify to a certain contrast of the zinc concentration in soils depending on the terrain and flora of the area and allow a comprehensive approach to solving the problems associated with the contamination of the landscapes of military facilities with the zinc trace element and its compounds. This approach helps to reduce the dangerous concentration of zinc in water bodies and soils of the military facilities of the Armavir range in the shortest possible time and to maintain the zinc content in the water-soil-plant system at an acceptable level. However, an integral part of the activities aimed at cleaning soil from zinc is the destruction of the contaminated plants. Plants do not inactivate heavy metals, but only accumulate them in their tissues; therefore, the situation of a critical accumulation of zinc at the place of destruction of plants may be the subject of further research and discussions.

\section{REFERENCES}

1. Avakyan, K.M., Achkanov, A.Ya., Podlesny, I.V. 2017. Soil Resources of the Kuban River Estuary and Their Agro-Industrial Grouping. Bulletin of the NTI All-Russian Research Institute of Rice, 24, 51-54.

2. Bugaevsky, V.K. 1971. Movable Components in the Meadow Soils of the Forest-and-Steppe Areas. In: Brief Outline Reports "Moscow University of Agriculture". Publishing House of the Moscow University, Moscow, pp. 195-197.
3. Bugaevsky, V.K. 2017. Development of Saline Soil and Waterlogged Soil. In: Recommendations for Rice Cultivation in Krasnodar Krai. All-Russian Research Institute of Rice, Krasnodar, pp. 10-15.

4. Cherednichenko, L.I. 1994. Patterns of Development of Landslides on the Black Sea Coast (AnapaTuapse). In: Geography of Krasnodar Krai Krasnodar, pp. 13-15.

5. Chernov, A.V. 1983. Geomorphology of the HighWater Beds of Plain Rivers. MSU Publ., Moscow.

6. Danilov-Danilyan, V.I. (Ed.). 1997. Ecology, Nature Conservation and Environmental Safety. MNEPU Publ., Moscow.

7. Durach, C.F., Wiengarten, F. 2017. Environmental management: The impact of national and organisational long-term orientation on plants' environmental practices and performance efficacy. Journal of Cleaner Production, 167, 749-758. https://doi. org/10.1016/j.jclepro.2017.08.183

8. Gosselin, F., Cordonnier, T., Bilger, I., Jappiot, M., Chauvin, C., Gosselin, M. 2018. Ecological research and environmental management: We need different interfaces based on different knowledge types. Journal of Environmental Management, 218, 388-401. https://doi.org/10.1016/j.jenvman.2018.04.025

9. Ladyman, M.K., Temple, T.J., Piperakis, M.M., Fawcett-Hirst, W. Gutierrez-Carazo, E., Coulon, F. 2019. Decision Framework for the environmental management of explosive contaminated land. Science of The Total Environment, 690, 730-738. https://doi.org/10.1016/j.scitotenv.2019.06.360

10. Puppim de Oliveira, J.A. 2019. Intergovernmental relations for environmental governance: Cases of solid waste management and climate change in two Malaysian States. Journal of Environmental Management, 233, 481-488. https://doi.org/10.1016/j. jenvman.2018.11.097

11. Ruseeva, Sh., Narodetskaya, Sh., Dunaevsky, B.V. (Eds.). 1976. Agroclimatic Resources of Krasnodar Krai. Gidromet-Izdat, Leningrad.

12. Todaro, N.M., Testa, F., Daddi, T., Iraldo, F. 2019. Antecedents of environmental management system internalization: Assessing managerial interpretations and cognitive framings of sustainability issues. Journal of Environmental Management, 247, 804815. https://doi.org/10.1016/j.jenvman.2019.06.106

13. Virapongse, A., Brooks, S., Covelli Metcalf, E., Zedalis, M., Gosz, J., Kliskey, A., Alessa, L. 2016. A social-ecological systems approach for environmental management. Journal of Environmental Management, 178, 83-91. https://doi.org/10.1016/j. jenvman.2016.02.028

14. Wallace, K.J., Jago, M. 2018. Category mistakes: A barrier to effective environmental management. Journal of Environmental Management, 199, 13-20. https://doi.org/10.1016/j.jenvman.2017.05.029 